BAOJIE WANG, Ph.D. ${ }^{1}$

E-mail: wangbj2@163.com

XIANGBEI XUE, Master's Degree Candidate ${ }^{1}$

E-mail: xiangbeixue7@163.com

XIAOJIAN HU, Ph.D. ${ }^{2,3}$

(Corresponding author)

E-mail: huxiaojian@seu.edu.cn

${ }^{1}$ School of Highway, Chang'an University

Middle Section of Nan'er Huan Road, Xi'an, 710064, China

2 Jiangsu Key Laboratory of Urban ITS, Southeast University

Southeast University Road \#2, Jiangning District, Nanjing, 211189, China

3 Jiangsu Province Collaborative Innovation Center of

Modern Urban Traffic Technologies, Southeast University

Southeast University Road \#2, Jiangning District,

Nanjing, 211189, China
Traffic in the Cities

Preliminary Communication

Submitted: 25 Oct. 2017

Accepted: 21 Jan. 2019

\title{
EVALUATING THE IMPACTS OF MODERN STREETCAR TRACKS ON BICYCLING THROUGH AN INTERSECTION
}

\begin{abstract}
Bicycle traffic flow suffers from the impact of tracks at an intersection in which a modern streetcar route is laid. The primary objective of this study involves discussing the impacts of modern streetcar tracks on bicycling through an intersection and developing a quantitative approach to calculate bicycle delay. Field investigations are conducted at eight sites in Nanjing and Shenyang, China. The sites are related to five intersections. Two of the five intersections are designed with a central modern streetcar style of track. Other two intersections operate on a roadside style of track and the last intersection is without tracks. The impact of the differences in bicycle speed are tested at each site based on the observed data. The results show that modern streetcar tracks exert a significant influence on bicycle speed and bicycling behavior and lead to delay, discomfort and unsafe conditions. Furthermore, a model is proposed to predict bicycle delay caused by modern streetcar tracks. The proposed model achieved a relatively accurate prediction. The findings of this study help in adequately understanding the impacts of modern streetcar tracks on bicycling. The results also suggest that longer crossing times should be used in signal design for bicycling at an intersection in which a modern streetcar route is laid.
\end{abstract}

\section{KEY WORDS}

modern streetcar tracks; bicycling behavior; bicycle speed; acceleration and deceleration; bicycle delay;

\section{INTRODUCTION}

Modern streetcars and bicycles are commonly recognized as transportation modes with low energy consumption, low air pollution and low road occupation. They are advocated globally and are characterized by significant progress, particularly in China. Over the past decade, the operating mileage of modern streetcars in China increased from $20.2 \mathrm{~km}$ in 2005 to $223.3 \mathrm{~km}$ in 2017 , with an average annual growth rate of $16.9 \%$. Simultaneously, the number of bicycles reached 370 million [1]. Both streetcars and bicycles provide individuals with convenience, economic benefits and flexible mobility. The trend of rapid developments with respect to streetcars and bicycles is expected to continue for the next few years in China.

A modern streetcar constitutes a light rail transit system. Although there is significant variation in its characteristics, its intrinsic properties include allocation with mostly shared or segregated right-of-way and operation on a road surface [2]. With respect to China, modern streetcars are mostly developed in rich areas such as the cities of Shanghai, Nanjing, Tianjin and Suzhou. Segregated right-of-way for a modern streetcar is common on roads with the aim to improve efficiency and safety. This helps modern streetcars in avoiding most obstacles during operations.

Additionally, a modern streetcar shares the rightof-way with other traffic modes at an intersection. It changes the channelization, signal control program and traffic capacity of an intersection. Its tracks affect general traffic behaviors. A decrease in speed constitutes the most typical behavior. Bicycles are more vulnerable in terms of safety, comfort and stability, and thus they are the first to bear the brunt. However, there is a paucity of research examining the impacts of modern streetcar tracks on bicycling.

The primary objective of this study involves proposing and demonstrating a quantitative approach to evaluate the impacts of modern streetcar tracks on bicycling through an intersection. More specifically, 
the study includes the following three tasks: (1) analyzing the bicycle speed changes caused by modern streetcar tracks at an intersection by means of applying statistical methods to field data; (2) assessing the impacts of different modern streetcar styles of tracks; and (3) evaluating bicycle delay by exploring an appropriate model. The findings of this study can contribute to understanding the modern streetcar track effects on bicycling through an intersection.

This paper is organized into five sections. The next section presents a review of previous studies. This is followed by data collection, which describes two popular styles of modern streetcar track design and three types of conflict between bicycles and tracks and explains the survey method. Statistical methods and prediction models are discussed in the Methodology section. This is followed by the Results of Data Analysis section in which statistical results and model validity are examined. Finally, the main conclusions of the study and promising directions for future research are presented in the last section.

\section{LITERATURE REVIEW}

Bicycling has experienced considerable growth in North America, Europe and Asia [1, 3-5]. Recent studies examined bicycling behavior with various bicycle-related roadway measures [6]. The main disadvantage of bicycling involves an intersection [7].

Primarily, most surveys are focused on bicycling behavior at signalized intersections. They provide insights on bicycling crossing speed, acceleration, deceleration and perception of risk and comfort. Fu et al. measured bicycle speed across the road and pointed out that adult bicyclists ride through the street with an average speed of $5.23 \mathrm{~m} / \mathrm{s}$ [8]. Publications by AASHTO, Forester, Rubins and Ling suggest that the following speeds should accommodate $98 \%$ of bicyclists: $5.36 \mathrm{~m} / \mathrm{s}$ for advanced bicyclists, $3.66 \mathrm{~m} / \mathrm{s}$ for basic bicyclists and $2.77 \mathrm{~m} / \mathrm{s}$ for children. Additionally, $85 \%$ of bicyclists should be able to clear signals for speeds that are $20 \%$ higher than the aforementioned speeds [9-12]. Bicycle speeds vary and are based on bicycling environment and intersection designs. Taylor measured comfortable acceleration and deceleration under normal conditions and pointed out that the mean comfortable acceleration and deceleration corresponded to $0.46 \mathrm{~m} / \mathrm{s}^{2}$ and $-2.29 \mathrm{~m} / \mathrm{s}^{2}$, respectively [13-14]. Jiang et al. highlighted that 90.1 percent of bicycling decelerations range from -0.014 to $-0.8 \mathrm{~m} / \mathrm{s}^{2}$ based on investigation data in Beijing [15].

Since vibration is perceived by bicyclists as one of the most important indicators of bicycling comfort, researchers also examined the impact of road surface quality on bicycling [16]. Vansteenkiste et al. analyzed bicycling behaviors of five participants on a high-quality and a low-quality bicycle track. They concluded that there is no significant difference in speed between the low-quality and the high-quality bicycle tracks, although there is an apparent decrease in the level of bicycling comfort [17]. Botma simplified hindrances experienced by bicyclists due to their interactions or maneuvers and divided them into passing events and meeting events [18]. Wu et al. evaluated the impacts of pavement damage on bicycle traffic flow on exclusive bicycle paths [19]. Li et al. studied bicycle passing events on physically separated bicycle roadways in China and proposed a quantitative method of evaluating the service level for bicycling [20-21]. Landis and Handy proposed a methodology to address the level of service for bicycling through movements at signalized intersections. This provides a measure of the level of safety and comfort experienced by bicyclists riding through an intersection [7].

Signals are required to provide an adequate clearance interval for bicyclists entering at the end of the green interval. Thus, accurate estimates of crossing times for bicycling are essential for a safe and efficient design of traffic signals. AASHTO proposed models to calculate the bicycling clearance interval and minimum green time [9]. Rubins and Handy collected data on bicycling crossing times for different crossing distances near the University of California at Davis campus and provided a methodology to measure bicycling crossing times [11]. The methodology was used in conjunction with the AASHTO equation to develop guidelines for estimating minimum green times and clearance intervals as a function of intersection width. However, existing results are mainly aimed at intersections that are designed normally and evenly.

A review of extant literature suggests that, although increased attention is focused on bicycling behavior and signal design at an intersection, relatively fewer studies consider the impacts of modern streetcar tracks on bicycling [6]. In order to fill this gap, the present study compared the running state changes of bicycles around modern streetcar tracks by using a statistical method and quantitatively analyzed bicycle delay related to modern streetcar tracks.

\section{DATA COLLECTION}

Currently, there are two popular styles of modern streetcar track design in China, namely central style and roadside style. They impact bicycling at distinct positions of an intersection. Three types of conflict are illustrated, as shown in Figure 1.

Central type: modern streetcar tracks are set in the center of the roadway at an intersection. The tracks affect bicycling when bicyclists approach the center of the intersection. 


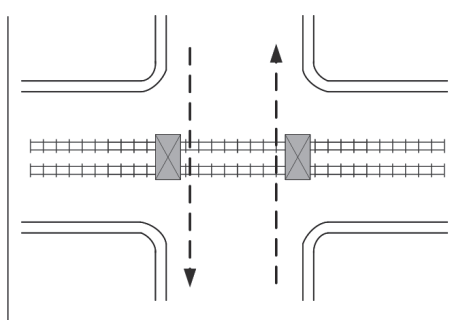

a) Central type

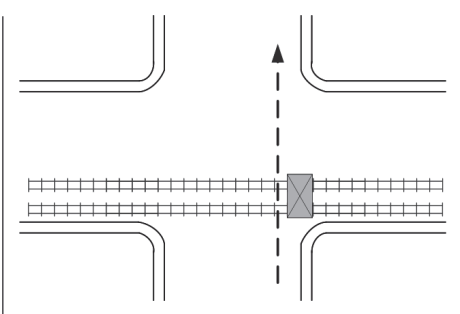

b) Near-end type

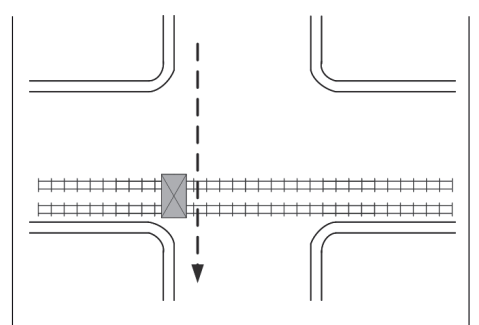

c) Far-end type

Conflict area

$\rightarrow$ Bicycle movement

H\#\|"\|l|H Modern streetcar tracks

Figure 1 - Schematic diagram of three conflict types

Near-end type: modern streetcar tracks are set near the sidewalk. The tracks influence passing bicycle speed at the time when bicyclists enter the intersection.

Far-end type: modern streetcar track design corresponds to the roadside style. The tracks disturb the bicycling behavior when bicyclists depart from the intersection.

For the purposes of the study, field investigations were conducted at five intersections in Nanjing and Shenyang, China. Three of the five intersections are located adjacent to each other along a single road at Hexi Region in Nanjing. The first one is designed with central modern streetcar tracks. The second one operates with a roadside style of modern streetcar track design. The third one corresponds to a normal intersection without modern streetcar tracks. Their data were collected on weekdays under fine weather conditions in the period between 6 April and 5 June 2015. The other two intersections were selected from the Qilin region of Nanjing and the Hunnan region of Shenyang. They operate with a central and roadside style of modern streetcar track design, respectively. Their data were collected in the period between 28 May and 23 June 2018.

Eight sites were designated to collect data at the five intersections. Sites 1 to 6 pertain to the three intersections of the Hexi Region. Site 1 focuses on the central type of conflict at the first intersection. Site 2 and Site 3 are located in the second intersection with roadside modern streetcar tracks. Site 2 is situated in the near-end type of conflict, while Site 3 is laid in the far-end type. Site 4 , Site 5 and Site 6 are located in the third intersection without modern streetcar tracks. They are treated as control groups with respect to Site 1 , Site 2 and Site 3, respectively. Site 7 and Site 8 belong to the other two intersections of the Qilin region and the Hunnan region. Site 7 focuses on the near-end type of conflict at the forth intersection. Site 8 is located at the fifth intersection with central modern streetcar tracks. A schematic of the survey area is illustrated as shown in Figure 2.
The collected data include geometric characteristics of the five intersections and videotapes of bicycling behaviors around the modern streetcar tracks. The geometric characteristics are measured with a measuring wheel. They include the widths of the intersection, the bicycle lane and the track area. A videotape is recorded with a video camera. The visual range exceeds a length of $40 \mathrm{~m}$ with modern streetcar tracks in the middle and is divided into the following three sections: upstream section, track area and downstream section.

Seven sections of videotapes are recorded at different times for each site. Each section corresponds to a length of $45 \mathrm{~min}$. The recorded videotapes are later manually reviewed in the laboratory. A trained graduate student is designated to record the time (within an accuracy of 0.1 seconds). The bicycle traffic flow and travel time of a sample bicycle passing through each section are recorded. The bicycle running speed in each section is calculated. Eventually, more than 310 bicycle samples are obtained at each site.

Moreover, the study concentrates on the changes in the running state of bicycles passing through a modern streetcar track area. Only the bicycles that arrive during a green interval are recorded. All stopped bicycles in the studied section are removed from the database irrespective of the type of hindrance that causes their stopping behavior. The geometric and bicycle traffic flow characteristics of the six studied sites are shown in Table 1.

\section{METHODOLOGY}

In the study, the bicycle speeds of the upstream section, the modern streetcar track area and the downstream section are defined as the U-speed, T-speed and D-speed, respectively.

Three methods are introduced in the analysis procedure and include (1) a T-test that is utilized to test the differences between the U-speed, T-speed and D-speed based on the collected data; (2) a prediction model that is proposed to predict the bicycle delay caused by modern streetcar tracks based on 


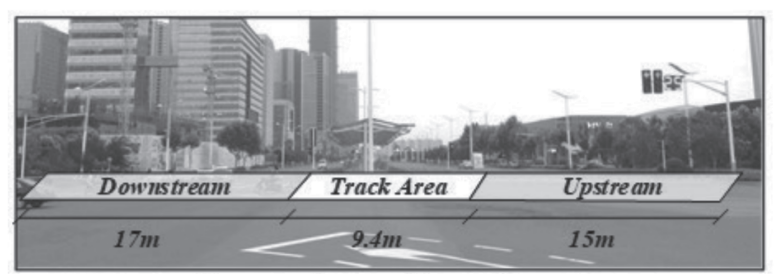

a) Central type with tracks-site 1

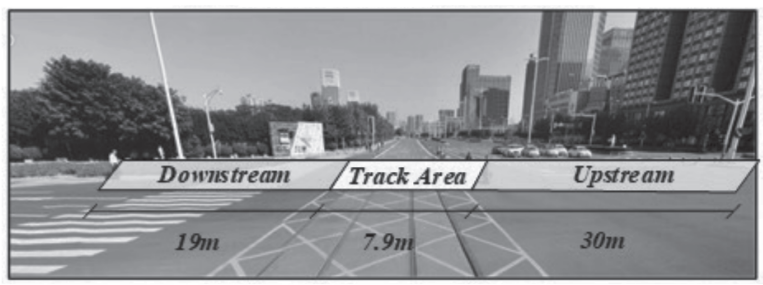

c) Far-end type with tracks-site 3

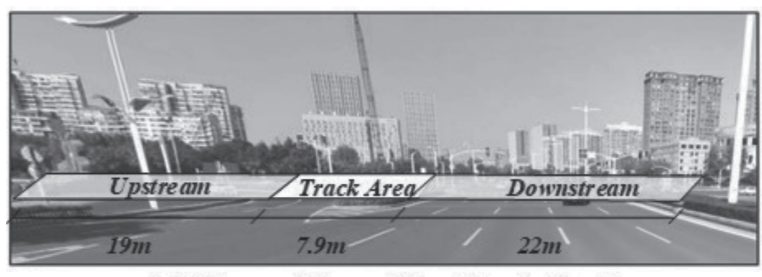

e) Near-end type without tracks-site 5

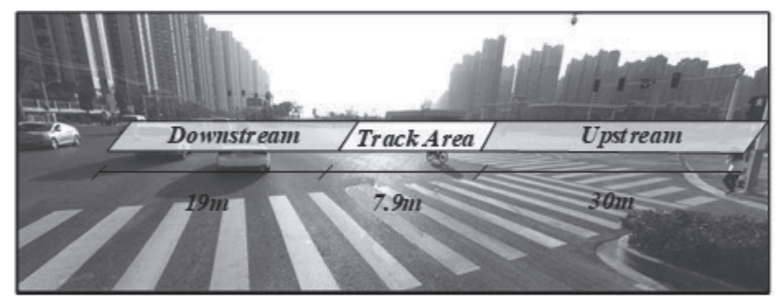

g) Near-end type with tracks-site 7

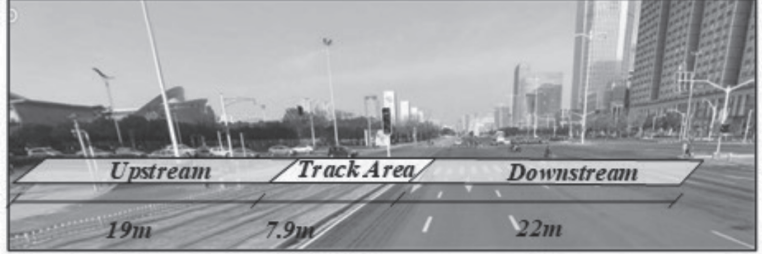

b) Near-end type with tracks-site 2

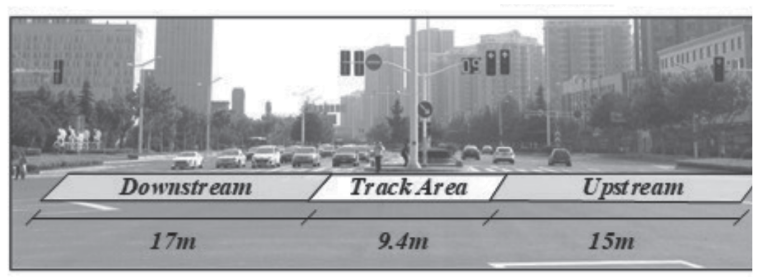

d) Central type without tracks-site 4

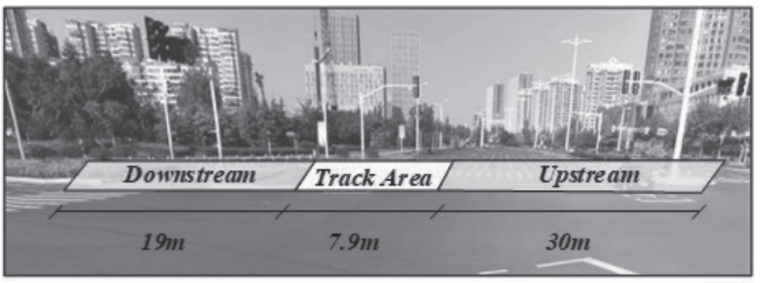

f) Far-end type without tracks-site 6

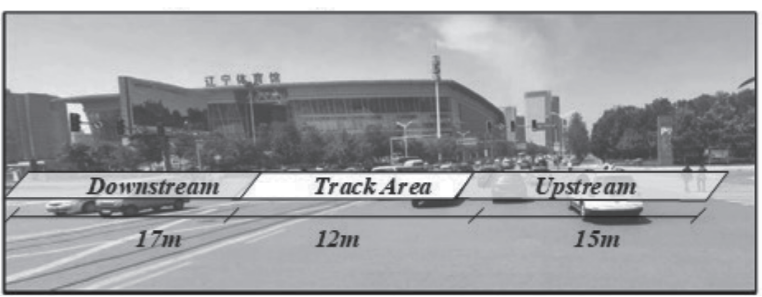

h) Central type with tracks-site 8

Figure 2 - Schematic of the survey area

kinematics theory; and (3) the mean absolute percent error that is used to measure the differences between the predicted value and the observed data.

\subsection{Testing speed differences}

A T-test is the most common method to test the significance of differences between two means from two independent samples.

It is assumed that $\mu_{1}$ denotes the mean of the U-speed, $\mu_{2}$ denotes the mean of the T-speed, and $\mu_{3}$ denotes the mean of the D-speed. The sample variance $S_{1}$ is obtained from the U-speed of sample size $n_{1}$, the sample variance $S_{2}$ is obtained from the U-speed of sample size $n_{2}$ and the sample variance $S_{3}$ is obtained from the U-speed of sample size $n_{3}$.

The null hypothesis states the following:

$\mathrm{H}_{0}$ : The two means are equal. Thus, it indicates that there are no significant differences between $u_{i}$ and $u_{j}$, and that the following equation is applicable: $u_{i}=u_{j}$

where $i=2$ and $j=1,3$.

$\mathrm{H}_{1}$ : The two means are not equal, and thus there are significant differences between $u_{i}$ and $u_{j}$. $u_{i} \neq u_{j}$

$\mathrm{H}_{0}$ can be rejected if the following expression holds: $Z=\frac{\left(\bar{X}_{i}-\bar{X}_{j}\right)-\left(u_{i}-u_{j}\right)}{\sqrt{\frac{S_{i}}{n_{i}}+\frac{S_{j}}{n_{j}}}} \geq Z_{a / 2}$

where $\left(u_{i}-u_{j}\right)$ denotes the difference between $u_{i}$ and $u_{j}$ under the null hypothesis, $\alpha(\alpha=0.05)$ denotes the level of significance and $Z_{\alpha / 2}$ denotes the $100(1-\alpha / 2) \%$ percentile of the standard normal distribution.

\subsection{Prediction model}

The kinematics theory adequately expresses the running state changes of bicycles around the modern streetcar track area. In this subsection, a model is 
Wang B, Xue X, Hu X. Evaluating the Impacts of Modern Streetcar Tracks on Bicycling Through an Intersection

Table 1 - Geometric and bicycle traffic flow characteristics of the studied sites

\begin{tabular}{|c|c|c|c|c|c|c|c|}
\hline No. & Site & Type & WI1 [m] & WT2 [m] & SNV3 & ATFB4 [bicycles/hour] & SS5 \\
\hline \multirow{7}{*}{1} & \multirow{7}{*}{$\begin{array}{l}\text { Jiangdong } \\
\text { Road-Hexi Avenue } \\
\text { intersection }\end{array}$} & \multirow{7}{*}{$\begin{array}{l}\text { Central with } \\
\text { tracks }\end{array}$} & \multirow{7}{*}{64} & \multirow{7}{*}{9.4} & 1 & 316 & 56 \\
\hline & & & & & 2 & 298 & 51 \\
\hline & & & & & 3 & 334 & 77 \\
\hline & & & & & 4 & 268 & 44 \\
\hline & & & & & 5 & 402 & 69 \\
\hline & & & & & 6 & 347 & 32 \\
\hline & & & & & 7 & 397 & 56 \\
\hline \multirow{7}{*}{2} & \multirow{7}{*}{$\begin{array}{c}\text { Jiangdong } \\
\text { Road-Olympic Avenue } \\
\text { intersection }\end{array}$} & \multirow{7}{*}{$\begin{array}{l}\text { Near-end with } \\
\text { tracks }\end{array}$} & \multirow{7}{*}{74} & \multirow{7}{*}{7.9} & 1 & 330 & 46 \\
\hline & & & & & 2 & 407 & 53 \\
\hline & & & & & 3 & 256 & 66 \\
\hline & & & & & 4 & 318 & 32 \\
\hline & & & & & 5 & 356 & 55 \\
\hline & & & & & 6 & 403 & 66 \\
\hline & & & & & 7 & 397 & 59 \\
\hline \multirow{7}{*}{3} & \multirow{7}{*}{$\begin{array}{c}\text { Jiangdong } \\
\text { Road-Olympic Avenue } \\
\text { intersection }\end{array}$} & \multirow{7}{*}{$\begin{array}{l}\text { Far-end with } \\
\text { tracks }\end{array}$} & \multirow{7}{*}{74} & \multirow{7}{*}{7.9} & 1 & 416 & 32 \\
\hline & & & & & 2 & 380 & 46 \\
\hline & & & & & 3 & 373 & 38 \\
\hline & & & & & 4 & 260 & 35 \\
\hline & & & & & 5 & 352 & 67 \\
\hline & & & & & 6 & 215 & 50 \\
\hline & & & & & 7 & 330 & 43 \\
\hline \multirow{7}{*}{4} & \multirow{7}{*}{$\begin{array}{c}\text { Jiangdong } \\
\text { Road-Mengdu Avenue } \\
\text { intersection }\end{array}$} & & & & 1 & 476 & 32 \\
\hline & & & & & 2 & 366 & 49 \\
\hline & & & & & 3 & 371 & 31 \\
\hline & & Central without & 56 & 9.4 & 4 & 414 & 68 \\
\hline & & & & & 5 & 399 & 50 \\
\hline & & & & & 6 & 294 & 43 \\
\hline & & & & & 7 & 407 & 59 \\
\hline & & & & & 1 & 461 & 80 \\
\hline & & & & & 2 & 385 & 77 \\
\hline & Jiangdong & & & & 3 & 251 & 36 \\
\hline 5 & Road-Mengdu Avenue & $\begin{array}{l}\text { Near-end } \\
\text { without tracks }\end{array}$ & 56 & 7.9 & 4 & 411 & 69 \\
\hline & intersection & & & & 5 & 354 & 72 \\
\hline & & & & & 6 & 403 & 54 \\
\hline & & & & & 7 & 383 & 37 \\
\hline & & & & & 1 & 370 & 77 \\
\hline & & & & & 2 & 453 & 54 \\
\hline & Jiangdong & & & & 3 & 380 & 36 \\
\hline 6 & Road-Mengdu Avenue & rar-end without & 56 & 7.9 & 4 & 268 & 33 \\
\hline & intersection & & & & 5 & 363 & 54 \\
\hline & & & & & 6 & 375 & 61 \\
\hline & & & & & 7 & 357 & 36 \\
\hline & & & & & 1 & 292 & 57 \\
\hline & & & & & 2 & 287 & 33 \\
\hline & Yunlianghe & & & & 3 & 282 & 42 \\
\hline 7 & Road-Nanwanying & $\begin{array}{l}\text { Near-end with } \\
\text { tracks }\end{array}$ & 66 & 7.9 & 4 & 370 & 45 \\
\hline & Avenue intersection & & & & 5 & 305 & 46 \\
\hline & & & & & 6 & 347 & 52 \\
\hline & & & & & 7 & 243 & 36 \\
\hline & & & & & 1 & 312 & 53 \\
\hline & & & & & 2 & 328 & 46 \\
\hline & Tiantan & & & & 3 & 412 & 58 \\
\hline 8 & Avenue-Hunnan Road & $\begin{array}{l}\text { Central with } \\
\text { tracks }\end{array}$ & 78 & 12 & 4 & 294 & 33 \\
\hline & intersection & & & & 5 & 302 & 48 \\
\hline & & & & & 6 & 350 & 41 \\
\hline & & & & & 7 & 364 & 52 \\
\hline
\end{tabular}

WI1: The width of the intersection, WT2: The width of the track area, SNV3: The serial number of the videotape, ATFB4: The average traffic flow of the bicycle in each videotape section, SS5: The sample size 
proposed to predict the bicycle delay by using the kinematics theory. The derivation procedure is elaborated in the following section.

It is assumed that bicycles maintain a fixed speed of $v_{t}$ when they pass through the modern streetcar track area and that the width of the track area corresponds to $s_{t}$. Bicycles reduce their speed from $v_{u}$ to $v_{t}$ with a deceleration of $a_{u}$ in the upstream section, and the decelerating distance corresponds to $s_{u}$. Similarly, bicycles increase their speed from $v_{t}$ to $v_{d}$ with an acceleration of $a_{d}$ in the upstream section and the accelerating distance corresponds to $s_{d}$. The process schematic of bicycles passing through a modern streetcar track area is shown in Figure 3.

Based on kinematics theory, two equations are established in the upstream and downstream sections as follows:

$$
\begin{aligned}
& v_{t}^{2}-v_{u}^{2}=2 a_{u} S_{u} \\
& v_{d}^{2}-v_{t}^{2}=2 a_{d} S_{d}
\end{aligned}
$$

Subsequently, the decelerating and accelerating distances are obtained as follows:

$s_{u}=\frac{v_{t}^{2}-v_{u}^{2}}{2 a_{u}}$

$s_{d}=\frac{v_{d}^{2}-v_{t}^{2}}{2 a_{d}}$

Additionally, in a situation in which modern streetcar tracks do not exist at an intersection, the bicycle travel time for a distance of $s_{u}+s_{t}+s_{d}$ is obtained as follows:

$$
t=\frac{s_{u}+s_{t}+s_{d}}{v_{m}}
$$

Otherwise, the bicycle travel time is described as follows:

$$
t^{*}=\frac{s_{u}}{\frac{v_{u}+v_{t}}{2}}+\frac{S_{t}}{v_{t}}+\frac{s_{d}}{\frac{v_{d}+v_{t}}{2}}
$$

Furthermore, it is expressed as follows:

$$
t^{*}=\frac{s_{t}}{v_{t}}+\frac{v_{t}-v_{u}}{a_{u}}+\frac{v_{d}-v_{t}}{a_{d}}
$$

Finally, the delay of a bicycle caused by modern streetcar tracks is determined as follows:

$$
\text { Delay }=t^{*}-t
$$

In the above formula, $v_{m}$ denotes the mean value of the U-speed and D-speed. A delay of a bicycle caused by modern streetcar tracks can be determined with the prediction model based on field data.

\subsection{Goodness-of-fit measures}

The extent to which a model fits the observed data is described as goodness-of-fit. The goodness-of-fit is a description of the discrepancies between the predicted value and the observed data. Mean absolute percent error (MAPE) analysis exhibits an evident advantage in evaluating discrete data and does not include any sample size restrictions. In the study, the discrepancies between the predicted value and the observed data are correspondingly measured by a MAPE analysis. The MAPE analysis is determined by the formula as follows:

$M A P E=\frac{1}{n} \sum_{k=1}^{n}\left|\frac{P_{k}-O_{k}}{O_{k}}\right|$

where $n$ indicates the number of videotape sections, $P_{k}$ represents the predicated delay of bicycles for section $k$ and $O_{k}$ denotes the observed delay of bicycles for section $k$. The value of the MAPE analysis exceeds or equals 0 . A smaller value of the MAPE indicates a higher accuracy of the prediction model. The model perfectly explains the observed variation in a situation in which the value of the MAPE analysis corresponds to 0 .

\section{RESULTS OF DATA ANALYSIS}

\subsection{Impacts of modern streetcar tracks on bicycle speed}

Bicycle speeds of the eight sites are summed and illustrated as frequency histograms and cumulative distribution curves as shown in Figure 4. As shown in Figure 4, frequency histograms of U-speed with tracks are significantly higher than those of U-speed without tracks when values of the horizontal ordinate are less than $7 \mathrm{~m} / \mathrm{s}$. The cumulative distribution curves of T-speed with tracks are always located on the left side of the curves of T-speed without tracks. As for near-end type of conflict, frequency histograms of T-speed with tracks mainly fall to zero when values of

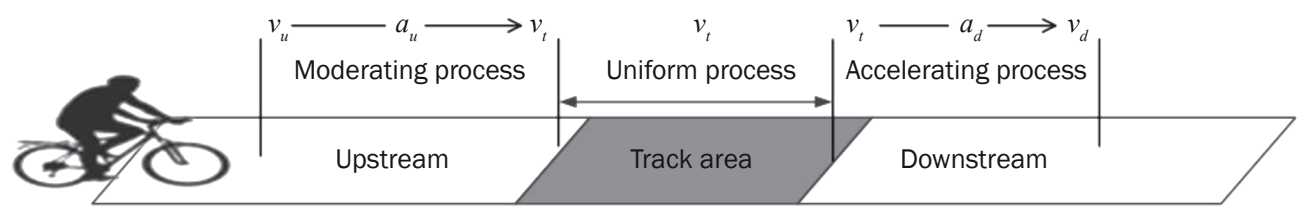

Bicycle movement

Figure 3 - Process schematic of bicycles passing through track area 


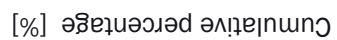

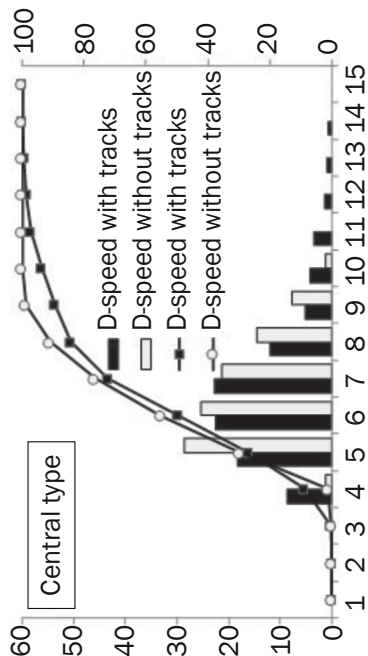

[\%] uo!̣ıodold Kouənbəג

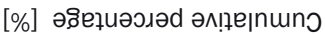

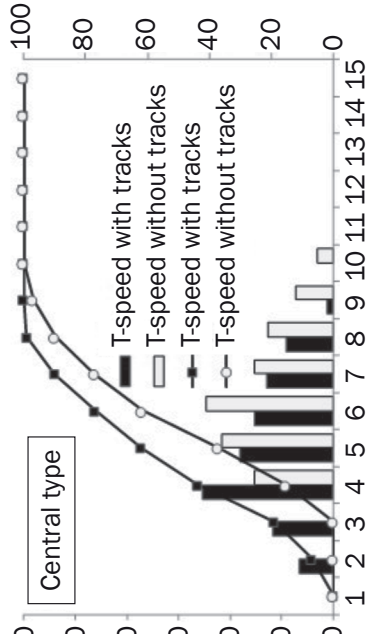

8 우

[\%] uo!̣ıodold Кэuәnbəג

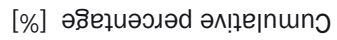

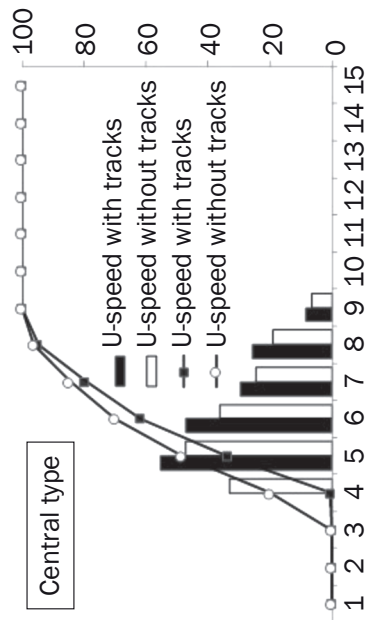

8 ㅇํ 우

[\%] uo!̣ıodold Кэuәnbəג

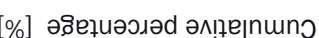

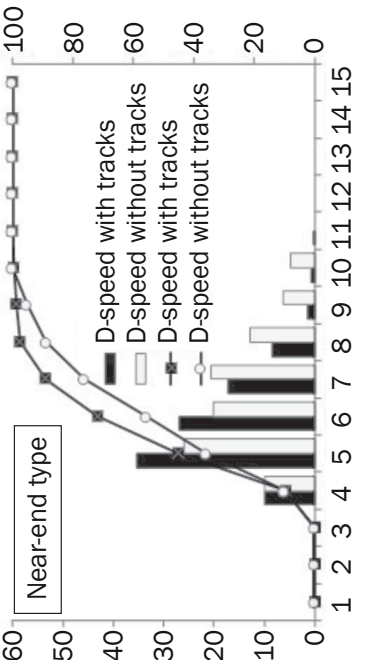

[\%] uo!̣ıodoıd Kouənbəגঊ

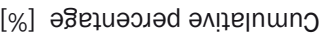

어 $\infty \circ$ ㅇ

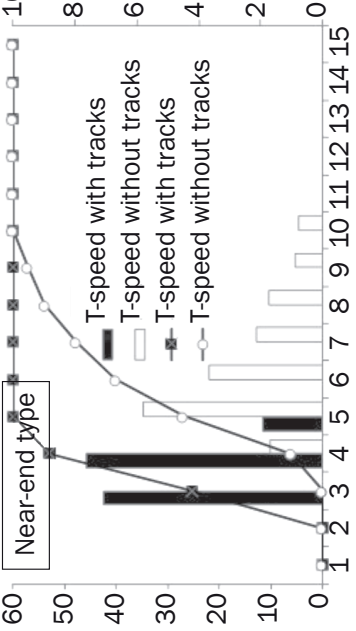

[\%] uo!̣ıodoıd Кэuәnbəג

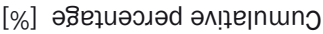

융

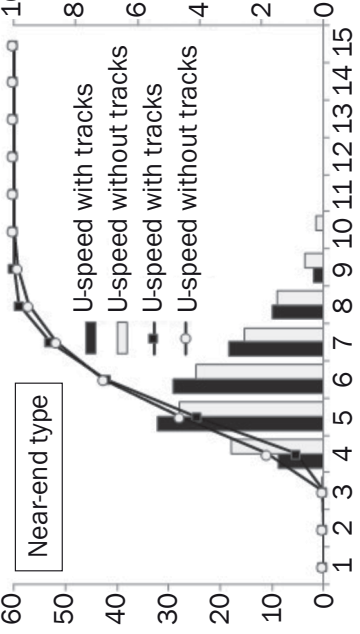

[\%] uo!̣ıodold Кэuәnbəג

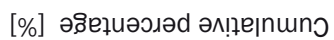

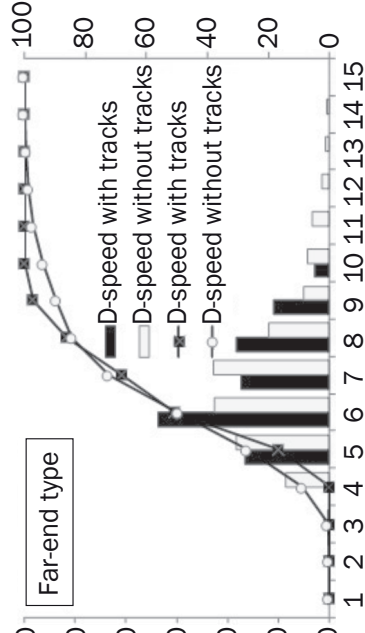

8 유 우

[\%] uo!ııodold Кouənbəג

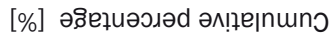

아 $\infty$ 웅ㅇ

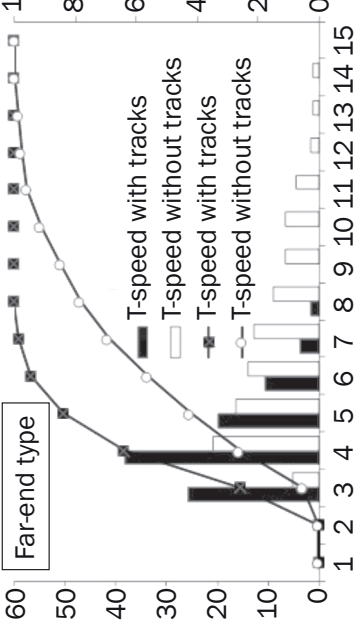

[\%] uo!̣ıodold Кэuәnbəג」

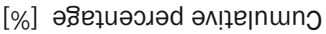

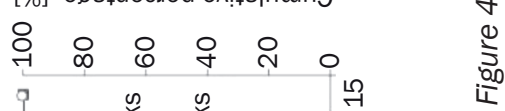


Table 2 - Summary statistics of the bicycle speed at the eight sites

\begin{tabular}{|c|c|c|c|c|c|c|c|c|c|}
\hline & & Site 1 & Site 2 & Site 3 & Site 4 & Site 5 & Site 6 & Site 7 & Site 8 \\
\hline \multicolumn{2}{|l|}{ Sample size } & 385 & 377 & 311 & 332 & 425 & 351 & 311 & 331 \\
\hline \multirow{3}{*}{$\begin{array}{l}\text { Standard } \\
\text { deviation } \\
{[\mathrm{m} / \mathrm{s}]}\end{array}$} & U-Speed & 1.16 & 1.13 & 0.95 & 1.41 & 1.38 & 1.22 & 0.99 & 1.09 \\
\hline & T-Speed & 0.94 & 0.52 & 1.14 & 1.56 & 1.54 & 2.55 & 0.40 & 0.67 \\
\hline & D-Speed & 0.71 & 1.24 & 1.31 & 1.35 & 1.56 & 1.96 & 1.32 & 1.33 \\
\hline \multirow{4}{*}{ T-test $(p<0.05)$} & U-Speed & \multirow{2}{*}{ Yes } & \multirow{2}{*}{ Yes } & \multirow{2}{*}{ Yes } & \multirow{2}{*}{ No } & \multirow{2}{*}{ No } & \multirow{2}{*}{ No } & \multirow{2}{*}{ Yes } & \multirow{2}{*}{ Yes } \\
\hline & T-Speed & & & & & & & & \\
\hline & T-Speed & \multirow{2}{*}{ Yes } & \multirow{2}{*}{ Yes } & \multirow{2}{*}{ Yes } & \multirow{2}{*}{ No } & \multirow{2}{*}{ No } & \multirow{2}{*}{ No } & \multirow{2}{*}{ Yes } & \multirow{2}{*}{ Yes } \\
\hline & D-Speed & & & & & & & & \\
\hline
\end{tabular}

the horizontal ordinate exceed $5 \mathrm{~m} / \mathrm{s}$. Additionally, the cumulative distribution curves of T-speed and D-speed with tracks almost coincide with those of T-speed and D-speed without tracks. This implies that bicycle speed is evidently decreased by modern streetcar tracks.

The T-test is used to quantitatively identify whether modern streetcar tracks significantly impact bicycle speeds. The mean values of U-speed, T-speed and D-speed for each site are compared to each other by using the T-test as shown in Table 2.

The results indicate that differences between U-speed, T-speed and D-speed are statistically significant at Sites 1-3 and Sites 7-8. This confirms the hypothesis that modern streetcar tracks are important hindrances in bicycle speed. Bicycles are forced to slow down due to safety and comfort concerns while approaching modern streetcar tracks. Subsequently, they gradually return to their ideal speed after passing the modern streetcar track area.

In contrast, differences are not statistically significant between U-speed, T-speed and D-speed with respect to Sites 4-6. This presents another perspective to explain the impacts of modern streetcar tracks on bicycling. It implies that bicyclists can maintain an ideal speed when they pass through an intersection without modern streetcar tracks.

\subsection{Impacts of modern streetcar tracks on bicycling behavior}

The means of U-speed, T-speed and D-speed at the eight sites are illustrated in Figure 5. At Sites 1-3 and 7-8, the mean of T-speed is significantly lower than those of U-speed and D-speed. The speed difference exceeds $1.57 \mathrm{~m} / \mathrm{s}$. Bicyclists prefer to slow down while approaching the modern streetcar track area and speed up after they pass through the area. As for Sites 4-6, the mean speed increases when bicyclists pass through the three sections in turn. The rate of the
Table 3 - Acceleration and deceleration at upstream and downstream sections in the eight sites

\begin{tabular}{|c|c|c||}
\hline \hline Site & $\begin{array}{c}\text { Upstream section } \\
{\left[\mathrm{m} / \mathrm{s}^{2}\right]}\end{array}$ & $\begin{array}{c}\text { Downstream section } \\
{\left[\mathrm{m} / \mathrm{s}^{2}\right]}\end{array}$ \\
\hline 1 & -0.53 & 0.61 \\
\hline 2 & -0.66 & 0.57 \\
\hline 3 & -0.34 & 0.87 \\
\hline 4 & 0.27 & 0.12 \\
\hline 5 & 0.26 & 0.07 \\
\hline 6 & 0.18 & 0.06 \\
\hline 7 & -0.69 & 0.53 \\
\hline 8 & -0.48 & 0.64 \\
\hline
\end{tabular}

increase is lower than $0.34 \mathrm{~m} / \mathrm{s}$. This indicates that bicyclists are inclined to move faster with a smooth increase in speed at the three sites.

The bicycle acceleration and deceleration of the upstream and downstream sections are shown in Table 3. For Sites 1-3 and Sites 7-8, the difference between acceleration and deceleration of Site 2 is the most significant, followed by Site 7. Additionally, the highest deceleration is observed in the upstream section of Site 7, while the highest acceleration is observed in the downstream section of Site 3. With respect to Sites 4-6, the bicycles continue to increase their speed. However, the acceleration does not exceed 0.27. This illustrates that the impact of the roadside track style on bicycling behavior exceeds that of the central style. Furthermore, it confirms behavior involving increasing speed and passing through a clear intersection.

\subsection{Prediction of bicycle delay}

The predicted bicycle delay in each videotape section of Sites 1-3 and 7-8 is calculated with the proposed prediction model. Each observed bicycle delay 


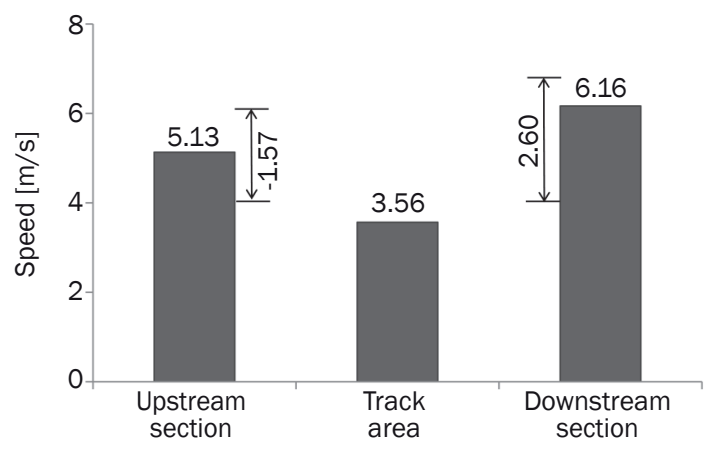

a) Central type with tracks-site 1

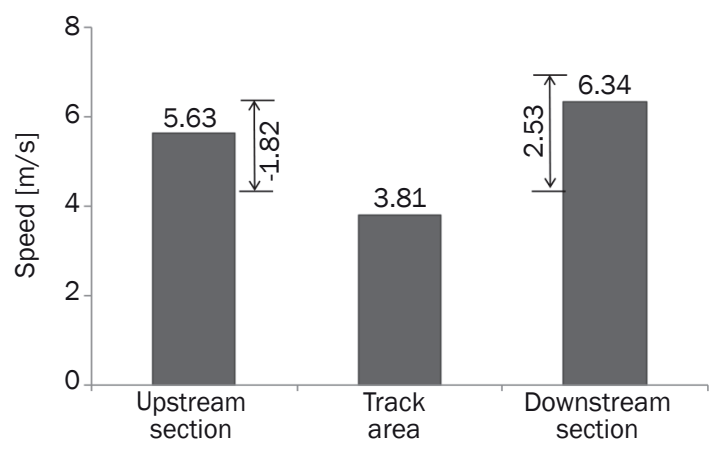

c) Far-end type with tracks-site 3

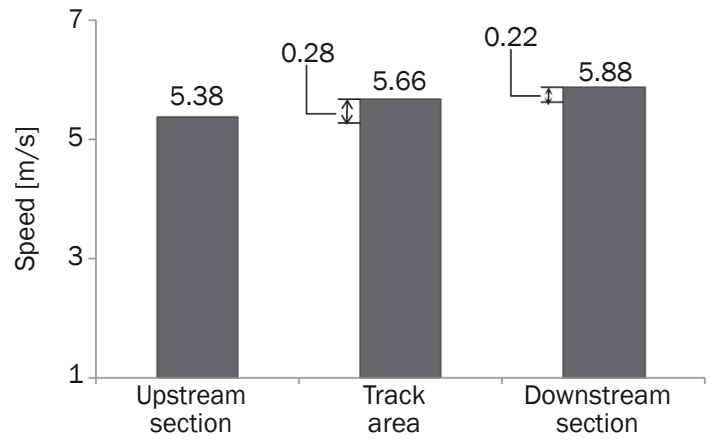

e) Near-end type without tracks-site 5

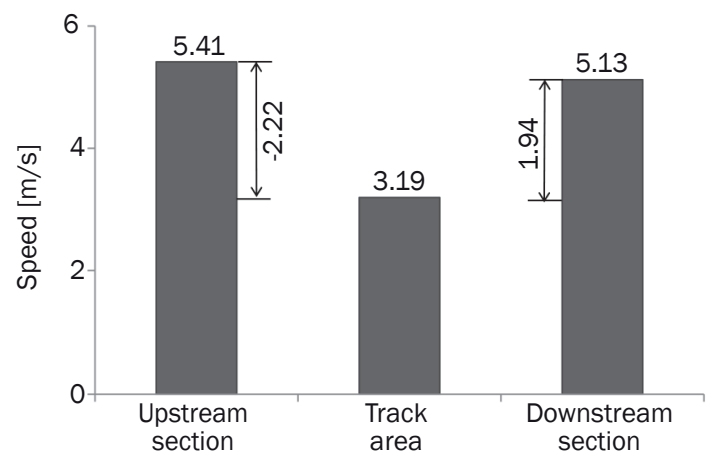

g) Near-end type with tracks-site 7

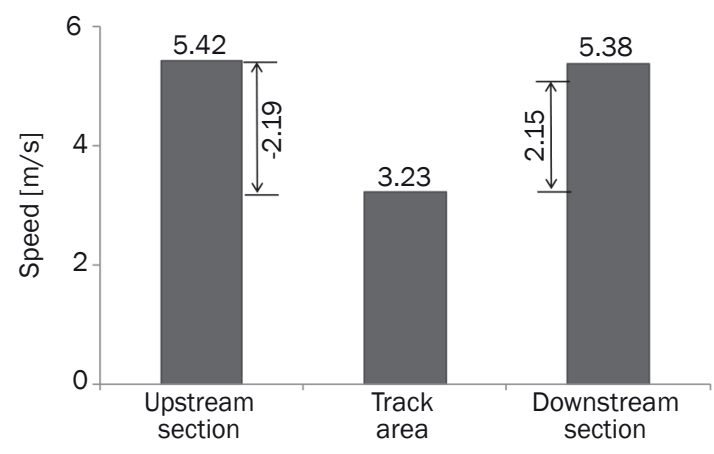

b) Near-end type with tracks-site 2

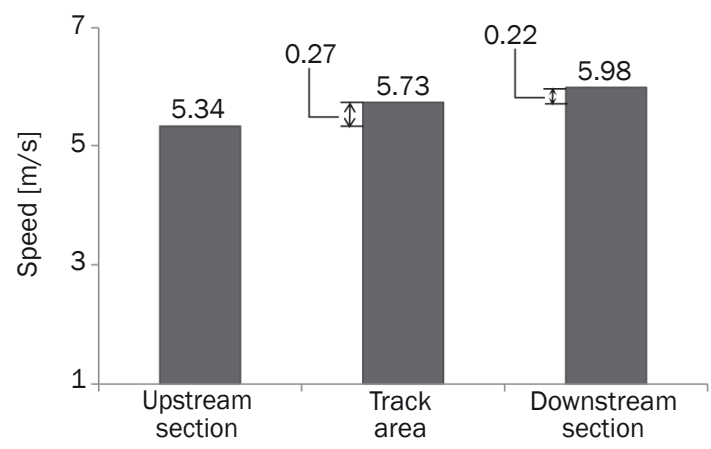

d) Central type without tracks-site 4

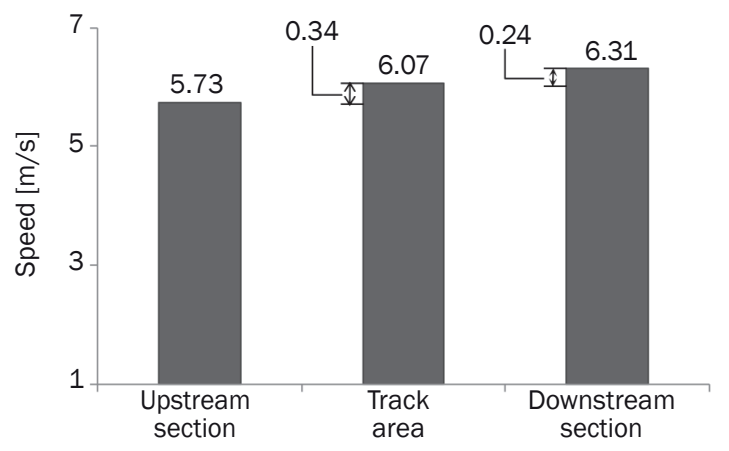

f) Far-end type without tracks-site 6

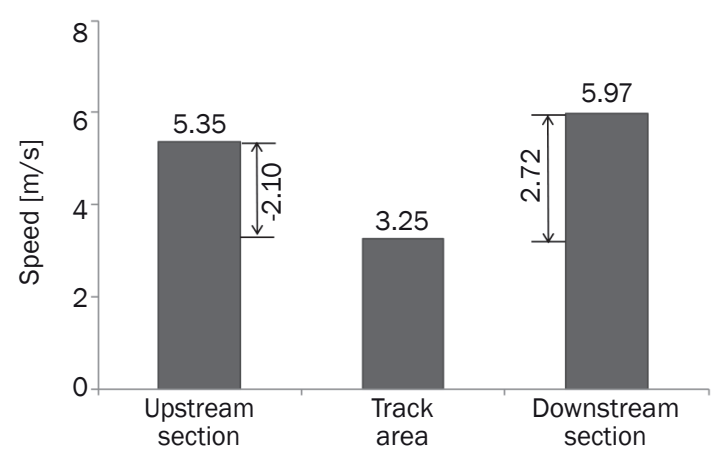

h) Central type with tracks-site 8

Figure 5 - Means of U-speed, T-speed, and D-speed at each site

is determined by using the observed travel time and the ideal travel time. The mean observed bicycle delay in each videotape is calculated correspondingly. The predicted and observed bicycle delays are compared and shown in Figure 6.
The slope of the regression line between the predicted and the observed delays corresponds to 0.817 . Data points of the five sites are scattered on both sides of the regression line. The delay related to the central type of conflict slightly exceeds those of the near-end 


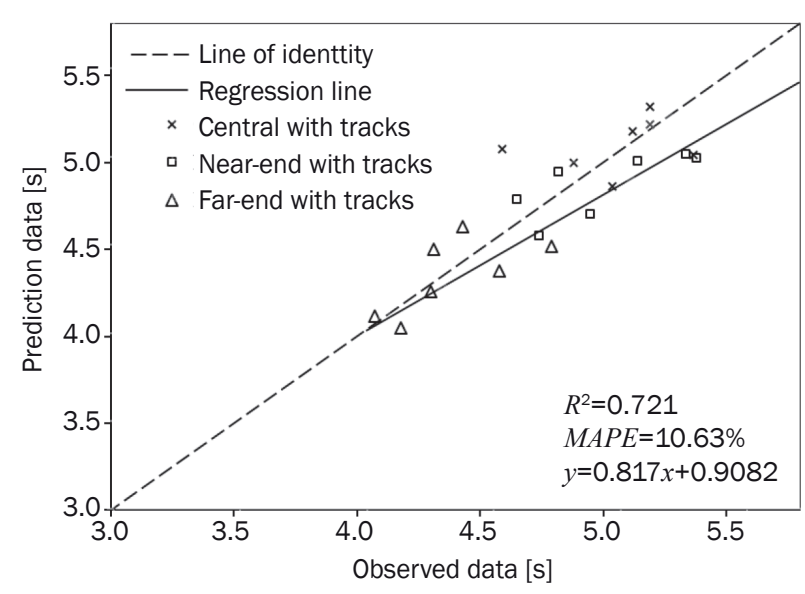

Figure 6 - Fitted relationships between the predicted and observed delays

and far-end type. The central track style causes a larger delay. The R2 is calculated as 0.721 while the value of the MAPE analysis corresponds to $10.63 \%$. The proposed prediction model is verified to accurately predict the bicycle delay.

\section{CONCLUSIONS}

The overall project objective involved evaluating the impacts of modern streetcar tracks on bicycling. Field data was collected at eight sites related to five intersections. A T-test was conducted to evaluate the significance of differences among the bicycle speeds at the three sections of each site. A delay prediction model was proposed to calculate the bicycle delay caused by modern streetcar tracks. The following five main conclusions were obtained based on the results of the data analysis.

1) Modern streetcar tracks have a significant effect on the bicycle speed at an intersection. This urgently requires related countermeasures to reduce or eliminate the impacts on bicycling safety, efficiency and comfort.

2) Influences with respect to the bicycling behavior differ across different styles of modern streetcar track designs. The roadside track style has a higher impact on bicycling behavior than the central style. Hence, the roadside track style leads to an increase in unsafe and uncomfortable conditions for bicycling.

3) Bicycle delay also differs across different modern streetcar track design styles. The central track style leads to a higher delay than the roadside track style. The results prove that the roadside track style exerts minor adverse effects on bicycling efficiency.

4) Bicyclists regard an intersection as an unsafe area. They are inclined to move faster and exhibit a smooth speed increase when passing through an intersection without any blocks.
5) The proposed model for the bicycle delay caused by modern streetcar tracks achieves relatively accurate predictions. The bicycle delay is calculated with the model by using field data.

The significant findings of this study include an explanation of the impacts of modern streetcar tracks on bicycling and provide a prediction model. The impact analysis results can be used as a reference with respect to modern streetcar track style selection for transportation managers. The prediction model is a quantitative method to predict the bicycle delay caused by tracks. The predictions can improve the Traffic Signal Timing Manual at an intersection in which a modern streetcar route is laid.

Admittedly, the study involves certain limitations and future studies are necessary to resolve them. Firstly, prediction accuracy is examined by using data from different intersections in the study. It is more effective to check the prediction accuracy by using before-and-after data at the same intersection. Secondly, the geometrical features of modern streetcar tracks and especially track altitude differences are not considered. Furthermore, it is necessary to collect data at relatively more sites and at sites located in other cities to validate the results in the study. Hence, future studies should focus on the aforementioned issues.

\section{ACKNOWLEDGMENT}

The study is supported by the National Natural Science Foundation of China (51478112) and the Fundamental Research Funds for the Central Universities of China (310821171006). The authors thank senior students from Transportation School of Southeast University for their assistance in field data collection and reduction. The authors also thank the Editor and anonymous reviewers for their constructive comments and valuable suggestions to improve the quality of the article.

王宝杰 博士

电子邮箱: wangbj2@163.com

长安大学 公路学院 西安市 陕西省 中国

薛祥北 硕士研究生

电子邮箱: xiangbeixue7@163.com

长安大学 公路学院 西安市 陕西省 中国

胡晓健 (通讯作者) 博士

电子邮箱: huxiaojian@seu.edu.cn

江苏省城市智能交通重点实验室 东南大学 南京 江苏 省 中国

江苏省现代城市交通技术协同创新中心 东南大学 南京 江苏省 中国

\section{交叉口的现代有轨电车轨道对自行车穿越骑行行为 的影响评价}

\section{摘要}

交叉口铺设的现代有轨电车轨道对自行车交通运行具 有重要影响。通过分析在交叉口现代有轨电车轨道影响下 
的自行车骑行特征, 提出一种计算自行车运行延误的计 算模型。选择中国沈阳和南京的 5 个交叉口作为数据采集 点, 提取自行车在这些位置的运行特征。其中，2个交叉 口铺设了路中直行式现代有轨电车轨道, 2 个交叉口铺设 了路侧直行式现代有轨电车轨道, 1个交叉口没有铺设任 何现代有轨电车轨道。采用数理统计理论对自行车的运行 指标进行分析, 结果显示现代有轨电车轨道对自行车的行 驶速度具有重要影响, 增加了自行车骑行延误、骑行不舒 适性和不安全性。同时, 构建了由现代有轨电车轨道导致 的自行车骑行延误计算模型, 并检验了模型预测精度。该 研究有助于深入了解交叉口铺设现代有轨电车对自行车行 驶带来的影响, 建议针对铺设轨道的交叉口采用更长的自 行车通行信号。

\section{关键词}

现代有轨电车轨道; 骑行行为; 自行车速度; 加速度和减 速度; 自行车延误

\section{REFERENCES}

[1] Chinese Statistical Yearbook. Chinese Statistical Press; 1998-2017.

[2] Transit Capacity and Quality of Service Manual. $3^{\text {rd }}$ edition. Transportation Research Board; 2013.

[3] Pucher J, Buehler R, Seinen M. Bicycling Renaissance in North America? An Update and Re-Appraisal of Cycling Trends and Policies. Transportation Research Part A: Policy and Practice. 2011;45(6): 451-475.

[4] American Community Survey. US Census Bureau; 2012.

[5] Martino A, Silvia M, Paola R. The Promotion of Cycling. European Parliament's Committee on Transportation and Tourism; 2010.

[6] Mead J, McGrane A, Zegeer C, Thomas L. Evaluation of Bicycle-Related Roadway Measures: A Summary of Available Research. North Carolina: Pedestrian and Bicycle Information Center; 2014.

[7] Landis BW, Vattikuti RM, Ottenberg TA, Petritsch M, Guttenplan LB, Crider L. Intersection Level of Service for the Bicycle Through Movement. Transportation Research Record: Journal of the Transportation Research Board. 2003;1828: 101-106.

[8] Fu L, Tian RR, Li LX, Chen YB, Sherony R. Bicycle Speed Analysis for Assessment of Bicyclist Pre-Collision System. The $25^{\text {th }}$ International Technical Conference on the Enhanced Safety of Vehicles, 5-6 June 2017, Detroit Michigan, United States.

[9] Guide for the Development of Bicycle Facilities. $4^{\text {th }}$ edition. American Association of State Highway and Transportation Officials; 2013.
[10] Forester J. Bicycle Transportation: A Handbook for Cycling Transportation Engineers. $2^{\text {nd }}$ edition. Cambridge, Mass: The MIT Press; 1994.

[11] Rubins D, Handy S. Times of Bicycle Crossings: Case Study of Davis, California. Transportation Research Record: Journal of the Transportation Research Board. 2005;1939: 22-27.

[12] Ling H, Wu JP. A Study on Cyclist Behavior at Signalized Intersections. IEEE Transactions on Intelligent Transportation Systems. 2004;5(4): 293-299.

[13] Taylor D. Analysis of Traffic Signal Clearance Interval Requirements for Bicycle-Automobile Mixed Traffic. Transportation Research Record: Journal of the Transportation Research Board. 1993;1405: 13-20.

[14] Taylor D. Contributions to Bicycle-Automobile Mixed-Traffic Science: Behavioral Models and Engineering Applications. Ph. D. Dissertation. The University of Texas, Austin; 1998.

[15] Jiang HF, Wen T, Jiang PP, Han H. Research on Cyclists Microscopic Behavior Models at Signalized Intersection. The $16^{\text {th }}$ Road Safety on Four Continents Conference, 15-17 May 2013, Beijing, China.

[16] Gao J, Sha AM, Huang Y, Hu LQ, Tong Z, Jiang W. Evaluating the Cycling Comfort on Urban Roads Based on Cyclists' Perception of Vibration. Journal of Cleaner Production. 2018;192: 531-541.

[17] Vansteenkiste P, Zeuwts L, Cardon G, Philippaerts R, Lenoir M. The Implications of Low-Quality Bicycle Paths on Gaze Behavior of Cyclists: A Field Test. Transportation Research Part F: Traffic Psychology and Behavior. 2014;23: 81-87.

[18] Botma H. Method to Determine Level of Service for Bicycle Paths and Pedestrian-Bicycle Paths. Transportation Research Record: Journal of the Transportation Research Board. 1995;1502: 38-44.

[19] Wu ZJ, Wang W, Hu XJ, Zhao D, Li ZB. Evaluating the Impacts of Pavement Damage on Bicycle Traffic Flow on Exclusive Bicycle Paths. The 94 ${ }^{\text {th }}$ Annual Meeting of the Transportation Research Board, 11-15 January 2015, Washington, D.C.

[20] Li ZB, Wang W, Liu P, Schneider R, Ragland DR. Investigating Bicyclists' Perception of Comfort on Physically Separated Bicycle Paths in Nanjing, China. Transportation Research Record: Journal of the Transportation Research Board. 2012;2317: 76-84.

[21] Li ZB, Wang W, Zhang YY, Lu J, Ragland D. Exploring Factors Influencing Bicyclists' Perception of Comfort on Bicycle Facilities. The $91^{\text {st }}$ Annual Meeting of the Transportation Research Board, 22-26 January 2012, Washington, D.C. 